\title{
STUDYING THE ELECTRICAL CHARACTERISTICS OF GRAIN UNDER VIBRATION ACTION
}

\author{
Alexander Ivashina, Andrey Adoshev, Valery Zhdanov, Vitaly Shemyakin \\ Stavropol State Agrarian University, Russia \\ av_ivashina49@mail.ru, adoshev@mail.ru,valery@yandex.ru,shi_ma@mail.ru
}

\begin{abstract}
Studies of the instrument error depending on the compaction of the grain sample in the sensor with free backfilling, forced sealing with a piston and under vibrating showed that the highest reproducibility of the readings, and therefore the lowest instrument error is provided, when exposed to vibration. Granular bulk materials change the volume only to a limited extent, even under the influence of external forces. The vibration action significantly reduces these forces, allowing the grains to be stacked more tightly. The stacking density depends on the vibration parameters. The use of vibration allows the stabilization of the volume density and simultaneous grain transportation through the sensor cavity. To use this method of preparing a grain sample, it is necessary to study its electrical specifications with this type of transportation. The vibration amplitude can be modified by changing the supply voltage of the electromagnetic vibrator. In this work, the dependences of the grain dielectric constant of different humidity in a high-frequency electric field on the vibration amplitude acting on it, are investigated. To determine the analytical expression that relates the grain electrical specifications with its moisture, volume density, temperature and frequency of the electric field, methods of active experiment planning are used in the work. Regression analysis of the experiment model showed its adequacy. The results are required and can be applied, for example, in the development of in-line and discrete grain moisture sensors.
\end{abstract}

Keywords: humidity, grain, vibration, electrical specifications.

\section{Introduction}

In modern devices for monitoring the moisture content of bulk materials, obtaining reliable and reproducible results is impossible without special sample preparation. Sample preparation is reduced to maintaining a constant density throughout the range of controlled humidity and is one of the most important tasks of sample formation for humidity control devices used in the flow of various bulk materials.

The nature of the sensor filling with bulk material of grain mass (GM) has a great influence on the measurement error. Studies of the device measurement error depending on the sample compaction in the sensor with free backfilling, forced sealing with a piston and under the influence of vibration showed that the highest reproducibility of the readings, and therefore the lowest measurement error is provided when exposed to vibration.

Since the grain mass is characterized by a weak bond between the individual grains, they move easily relative to each other, like liquid molecules. However, if the liquid is able to change the shape almost infinitely under its own weight, without changing the volume occupied by it, the bulk materials change the volume only limited, even under the influence of external forces.

With a free backfill, the grain mass is prone to the formation of an arch structure for stacking the grains due to the adhesive, jamming and friction forces between them. Vibrating action significantly reduces these forces, allowing the grains to fit more closely. The packing density depends on the vibration parameters.

Since the use of vibrational liquefaction for the purposes of monitoring the moisture content of the grain mass allows to solve two problems at once, that is the stabilization of the volume density with simultaneous export of the bulk mass through the cavity of the sensor, then to justify the possibility of using this method of preparing a sample of the grain mass, it is necessary to study its electrical properties with this type of transportation.

\section{Materials and methods}

The electrical characteristics of grain and seeds were studied by many authors [1-4].

The influence of the vibration frequency on the electrical properties of the grain mass has not been studied. To study the electrical properties of the grain mass, a vibrating table was developed and manufactured (Fig. 1) with a plane-parallel capacitor sensor attached to it.The vibration amplitude can be modified by changing the supply voltage of the electromagnetic vibrator. 
It is supposed to use a network of $220 \mathrm{~V}$ and $50 \mathrm{~Hz}$ to power the vibrator, while the permissible frequency deviation is $\pm 0.1 \mathrm{~Hz}$.

The dependences of the grain dielectric constant of different humidity on the amplitude of vibration acting on it are investigated.

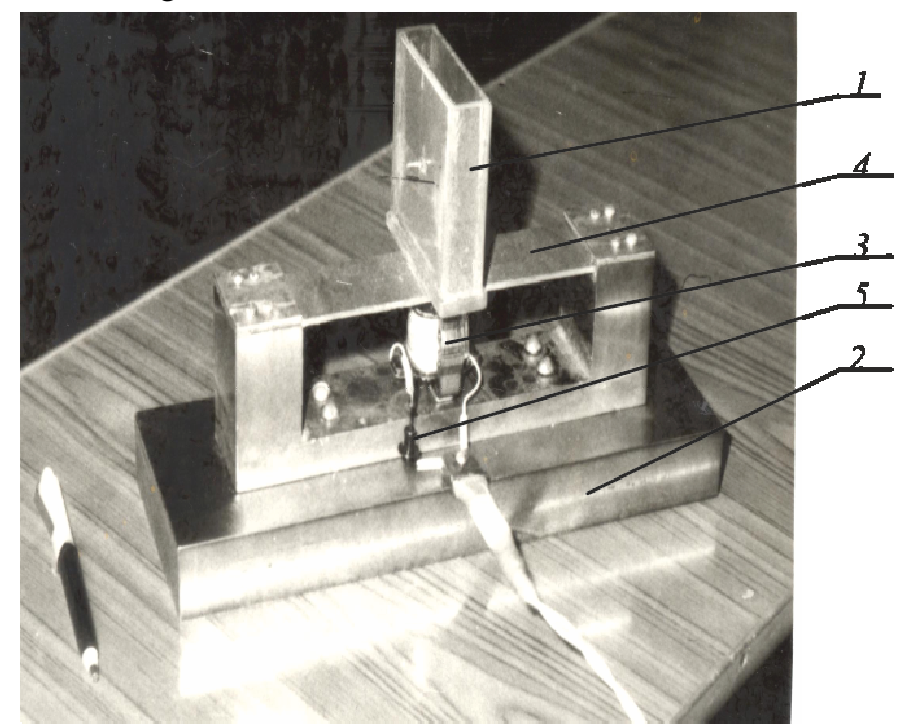

Fig. 1. Vibrating table to study electrical properties of grain mass: 1 - capacitor sensor; 2 - base; 3 - electromagnetic vibrator; 4 - elastic spring; 5 - rectifier

Figure 2 shows a scheme for measuring the dielectric constant of the grain mass under the vibration action of different amplitudes.

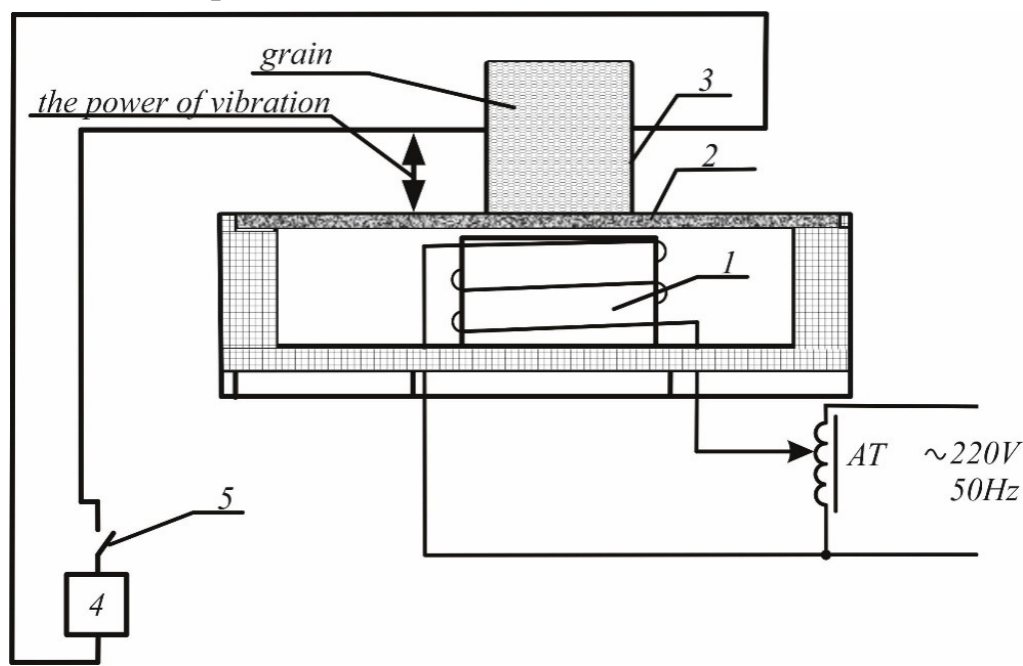

Fig. 2. Scheme of measuring dielectric constant of grain vibration: 1 - electromagnetic vibration exciter; 2 - metalplate - spring; 3 - plane-parallel capacitor sensor with grain;

4 - device for measuring the dielectric constant when exposed to a high-frequency electric field; 5 - one-way switch

To determine the analytical expression that relates the electrical characteristics of the grain mass with its moisture, volume density, temperature and frequency of the sinusoidal periodic electric field is written as $Y=F(W, P, T, f)$, we use the methods of active planning of the experiment. These methods make it possible to choose the optimal research strategy with incomplete knowledge of the process mechanism.

Planning was carried out on the basis of the three-level plan matrix of the Box experiment (B4), for which each factor can take values of $-1 ; 0 ;+1$.During the experiment, four variables were varied: the moisture content of the grain mass $(\mathrm{W}, \%)$, the frequency of the electric field $(f, \mathrm{MHz})$, the temperature $\left(T^{\circ}, \mathrm{K}\right)$, its volume density, which modified through a change in the amplitude factor $(\mathrm{A}$, 
$\mathrm{mm}$ ) of the vibration acting on the grain of wheat.Planning an experiment involves solving the issue of repetition of experience.

At the first stage, the reliability of the experiment results $\alpha$ (confidence probability) and the admissible error $\varepsilon$ are set. Usually, to determine the influence of various factors, the confidence probability $\alpha=0.7 \ldots 0.95$ is sufficient, accepted $\alpha=0.95$ and $\varepsilon=3 \delta$.

For the selected values of the confidence probability and the admissible error, the required number of experiment replications is determined, this number equals $k=3$.

On the basis of studying the works of foreign scientists [5-8], as well as taking into account the requirements for the type of the response function, the following levels of variables were proposed (Table 1).

Table 1

Variation levels of variables in terms of experiment B4 in coded and natural forms

\begin{tabular}{|c|c|c|c|c|c|}
\hline \multirow{2}{*}{ Accepted notation } & \multirow{2}{*}{$\begin{array}{c}\text { Code } \\
\text { mark }\end{array}$} & $\begin{array}{c}\text { Humidity, } \\
\mathbf{W}, \boldsymbol{\%}\end{array}$ & $\begin{array}{c}\text { Vibration } \\
\text { amplitudeA, } \\
\mathbf{m m}\end{array}$ & $\begin{array}{c}\text { Electric field } \\
\text { frequency } \boldsymbol{f}, \\
\mathbf{M H z}\end{array}$ & $\begin{array}{c}\text { Grain mass } \\
\text { temperatur } \\
\mathbf{e} \mathbf{T}^{\boldsymbol{o}} \mathbf{K}\end{array}$ \\
\cline { 3 - 6 } & & $x_{1}$ & $x_{2}$ & $x_{3}$ & $x_{4}$ \\
\hline Upper level & +1 & 30 & 2.5 & 10.0 & 327 \\
\hline Ground level & 0 & 22 & 1.5 & 5.5 & 305 \\
\hline Lower level & -1 & 14 & 0.5 & 1.0 & 283 \\
\hline Variability interval & & 8 & 1.0 & 4.5 & 22 \\
\hline
\end{tabular}

To obtain comparable results of the experiment and according to the generally accepted methods for the study of the electrical properties of the grain mass [1-8] a number of parameters were maintained constant.These parameters and their values are summarized in Table 2.

Table 2

Value of fixed factors in the study of grain mass electrical properties

\begin{tabular}{|c|c|c|c|c|c|c|}
\hline $\begin{array}{c}\text { Type } \\
\text { of } \\
\text { factor }\end{array}$ & $\begin{array}{c}\text { Time binning } \\
\text { after } \\
\text { moisturizing, } \\
\text { day }\end{array}$ & $\begin{array}{c}\text { Shape of the } \\
\text { acting } \\
\text { electric field }\end{array}$ & $\begin{array}{c}\text { Wheat } \\
\text { grade }\end{array}$ & Region & $\begin{array}{c}\text { Method of } \\
\text { moisture } \\
\text { test }\end{array}$ & $\begin{array}{c}\text { Electrode } \\
\text { material of } \\
\text { measuring } \\
\text { cells }\end{array}$ \\
\hline Value & 2 & Sinusoidal & Bezostaja-1 & $\begin{array}{c}\text { Stavropol } \\
\text { region }\end{array}$ & GOST & $\begin{array}{c}\text { Stainless } \\
\text { steel }\end{array}$ \\
\hline
\end{tabular}

The basis for obtaining and describing the results of the experiments is the regression analysis, which is based on obtaining the regression equation and its statistical study [1-8].

For the four-factor experiment, the Box matrix (B4), presented in Table 3, was chosen.

The regression equation for the four-factor experiment was taken as a polynomial model of the second degree (1), which is consistent with the results of many researchers [1-4].

$$
Y=b_{0} \sum_{i=1}^{n} b_{i} x_{i}+\sum_{i=1}^{n} b_{i j} x_{i}^{2}+\sum_{i=1}^{n} b_{i j} x_{i} x_{j} \text {. }
$$

Table 3

Box plan matrix (B4) for a four-factor experiment

\begin{tabular}{|c|c|c|c|c|c|}
\hline \multirow{2}{*}{$\begin{array}{c}\text { Sr. } \\
\text { No. }\end{array}$} & \multicolumn{4}{|c|}{ Experimental factors } & $\begin{array}{c}\text { Response } \\
\text { value }\end{array}$ \\
\cline { 2 - 6 } & $x_{1}$ & $x_{2}$ & $x_{3}$ & $x_{4}$ & $Y_{n}$ \\
\hline 1 & +1 & +1 & +1 & +1 & $Y_{1}$ \\
\hline 2 & +1 & +1 & +1 & -1 & $Y_{2}$ \\
\hline 3 & +1 & +1 & -1 & +1 & $Y_{3}$ \\
\hline 4 & +1 & +1 & -1 & -1 & $Y_{4}$ \\
\hline 5 & +1 & -1 & +1 & +1 & $Y_{5}$ \\
\hline 6 & +1 & -1 & +1 & -1 & $Y_{6}$ \\
\hline
\end{tabular}


Table 3 (continued)

\begin{tabular}{|c|c|c|c|c|c|}
\hline $\begin{array}{l}\text { Sr. } \\
\text { No. }\end{array}$ & \multicolumn{4}{|c|}{ Experimental factors } & $\begin{array}{c}\text { Response } \\
\text { value }\end{array}$ \\
\hline 7 & +1 & -1 & -1 & +1 & $Y_{7}$ \\
\hline 8 & +1 & $\begin{array}{ll}-1 \\
\end{array}$ & -1 & -1 & $Y_{8}$ \\
\hline 9 & -1 & +1 & +1 & +1 & $Y_{9}$ \\
\hline 10 & -1 & +1 & +1 & -1 & $Y_{10}$ \\
\hline 11 & -1 & +1 & -1 & +1 & $Y_{11}$ \\
\hline 12 & -1 & +1 & -1 & -1 & $Y_{12}$ \\
\hline 13 & -1 & -1 & +1 & +1 & $Y_{13}$ \\
\hline 14 & -1 & -1 & +1 & -1 & $Y_{14}$ \\
\hline 15 & -1 & -1 & -1 & +1 & $Y_{15}$ \\
\hline 16 & -1 & -1 & -1 & -1 & $Y_{16}$ \\
\hline 17 & +1 & 0 & 0 & 0 & $Y_{17}$ \\
\hline 18 & -1 & 0 & 0 & 0 & $Y_{18}$ \\
\hline 19 & 0 & +1 & 0 & 0 & $Y_{19}$ \\
\hline 20 & 0 & -1 & 0 & 0 & $Y_{20}$ \\
\hline 21 & 0 & 0 & +1 & 0 & $Y_{21}$ \\
\hline 22 & 0 & 0 & -1 & 0 & $Y_{22}$ \\
\hline 23 & 0 & 0 & 0 & +1 & $Y_{23}$ \\
\hline 24 & 0 & 0 & 0 & -1 & $Y_{24}$ \\
\hline
\end{tabular}

\section{Results and discussion}

For the research winter wheat "Bezostaya-1" was selected.

In the experiment, the effect on the dielectric constant (DC) of four factors was studied: the humidity of GMW \%, the amplitude of vibration emitted by the electromagnetic vibrator, A, mm; the electric field frequency $f, \mathrm{MHz}$; the GM temperature $T^{\mathrm{D}}, \mathrm{K}$.

Experimental data were taken using the shake-table (Fig. 1) and the measuring circuit presented in Figure 2.

The regression equation in coded form is:

$$
\begin{aligned}
& Y=6.296+2.032 X_{1}-0.711 X_{2}-0.951 X_{3}+0.297 X_{4}-0.218 X_{1} X_{2} 0.568 X_{1} X_{3}+ \\
& +0.119 X_{2} X_{3}+0.214 X_{1}^{2}-0.776 X_{2}^{2}+0.474 X_{3}^{2}-0.126 X_{4}^{2}
\end{aligned}
$$

Analysis of the regression equation (2) of the four-factor model according to the plan B4 at zero levels of humidity, frequency and temperature factors leads to the following expression for the response function (DC):

$$
Y=6.296-0.711 X_{2}-0.776 X_{2}^{2} .
$$

Obviously, the function has a maximum (Fig. 3). Differentiating expression (3) and equating the resulting expression to zero (4), we obtain

$$
\frac{d Y}{d X_{2}}=-0.711-0.776-2 \cdot X_{2}=0 \text {. }
$$

Hence, $X_{2}=-0.46$ and $Y=-6.46$. Thus, with the vibration amplitude $A=1.04 \mathrm{~mm}$, the maximum value of the volume density of GM is reached. With a further increase in the vibration amplitude, the value of the volume density decreases to the value of the grain nature.

This dependence $Y=f\left(X_{2}\right)$ can be explained by the fact that at the initial increasing vibration amplitudes ordering (compaction) of GM occurs by overcoming the internal friction forces of the grains against each other. After reaching the maximum value of the volume density and with further growth of the vibration amplitude, the loosening of GM occurs and, as a consequence, a decrease in its volume density and dielectric constant. 


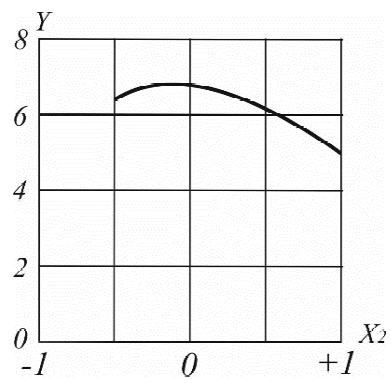

Fig. 3. Dependence of response function on vibration amplitude at zero humidity levels and frequencies

a)

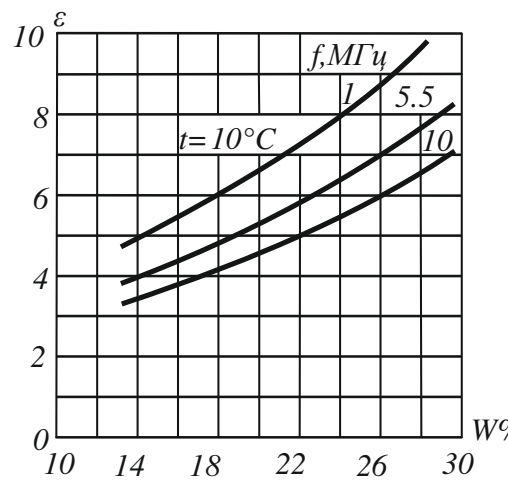

b)

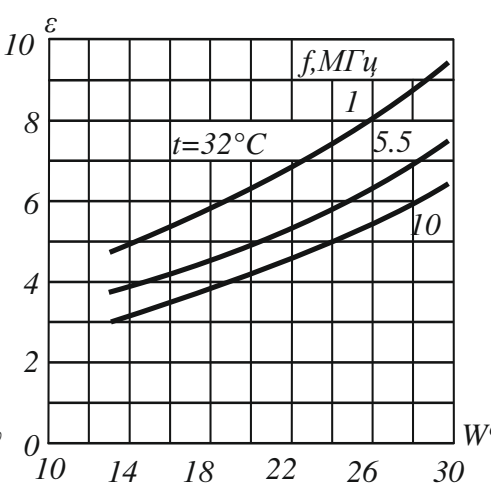

c)

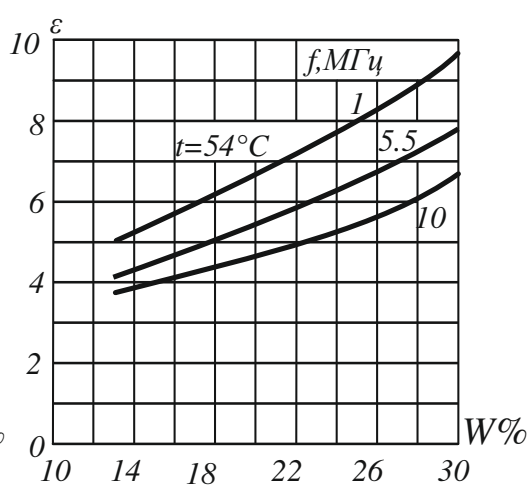

Fig. 4. Dependence of DC $(\varepsilon)$ of wheat grain "Bezostaya-1" on humidity at different frequencies and vibration amplitude $A=1.04 \mathrm{~mm}: \mathrm{a}-t=283^{\circ} \mathrm{K} ; \mathrm{b}-\mathrm{t}=305^{\circ} \mathrm{K} ; \mathrm{c}-t=327^{\circ} \mathrm{K}$

a)

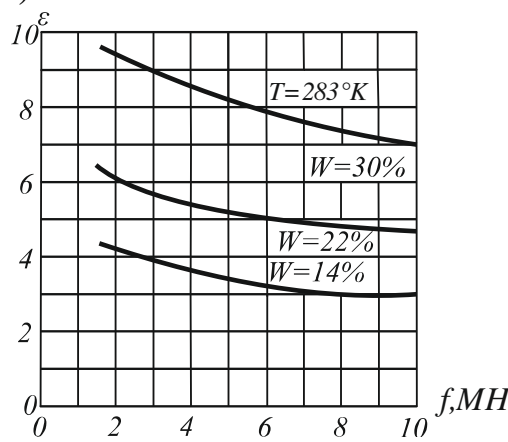

b)

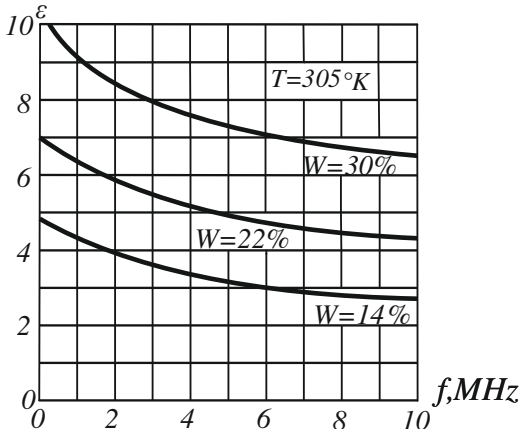

c)

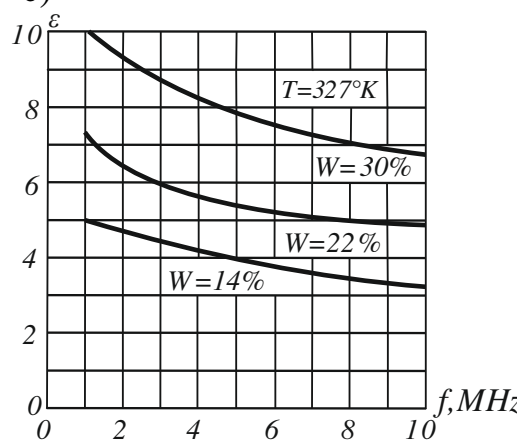

Fig. 5. Dependence of DC $(\varepsilon)$ of wheat grain "Bezostaya-1" on frequency at different humidities and vibration amplitude $\boldsymbol{A}=\mathbf{1 . 0 4} \mathrm{mm}: \mathrm{a}-t=283^{\circ} \mathrm{K} ; \mathrm{b}-\mathrm{t}=305^{\circ} \mathrm{K} ; \mathrm{c}-t=327^{\circ} \mathrm{K}$

Figures 4 and 5 show the DC dependencies of wheat grain ("Bezostaya-1") on humidity for different frequencies of the high-frequency electric field at different temperatures and the vibration amplitude $\mathrm{A}=1.04 \mathrm{~mm}$, constructed according to the regression equations (2) after decoding in accordance with the expressions (5):

$$
X_{1}=\frac{W-22}{8} ; X_{2}=\frac{A-1.5}{1} ; X_{3}=\frac{f-5.5}{4.5} ; X_{4}=\frac{t-32}{22} .
$$

Analysis of the moisture frequency characteristics $\varepsilon=f(w)$ shows that at $f=$ const with increasing humidity, DC increases. Its growth is observed with an increase in the temperature of the grain mass and is $\left(0.011\right.$ per ${ }^{\circ} \mathrm{K}$ to 0.015 per $\left.{ }^{\circ} \mathrm{K}\right)$ for the studied frequency range, therefore temperature compensation is required.

The dependence of DC of wheat "Bezostaya-1" on the vibration amplitude (Fig. 6) at different humidities and temperatures for frequencies $1 \mathrm{MHz}, 5.5 \mathrm{MHz}$ and $10 \mathrm{MHz}$ is extremum. At the same time, in the range of vibration amplitudes $0.5 \ldots 2.5 \mathrm{~mm}$ the relative change in DC is $8 \ldots 10 \%$. 
Thus, it can be concluded that it is necessary to introduce stabilization of the vibration amplitude in the flow device for preparing the GM sample.

a)

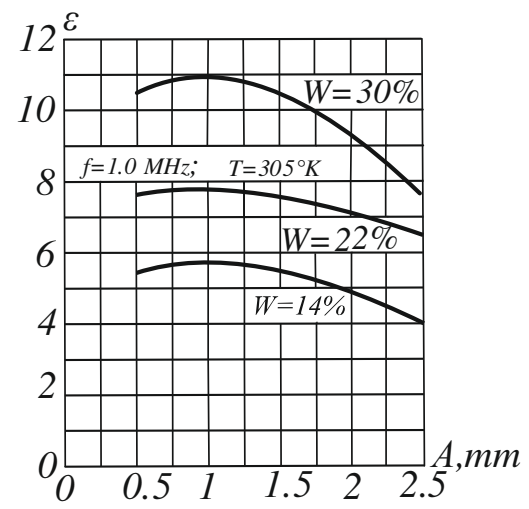

b)

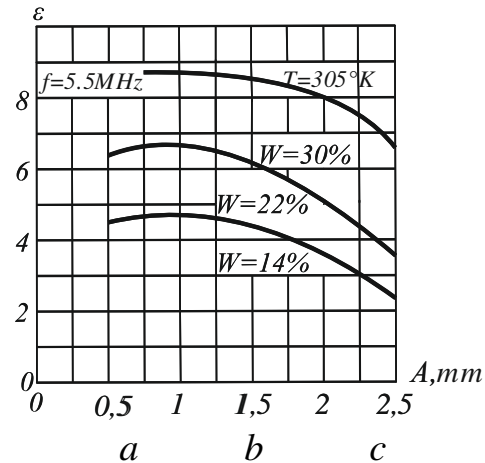

c)

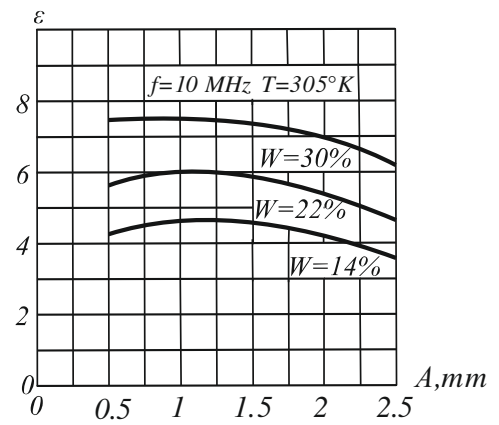

Fig. 6. Dependence of DC $(\varepsilon)$ of Bezostaja-1wheat grain on vibration amplitude at temperature $\boldsymbol{t}=305^{\circ} \mathrm{K}$ and various humidity: $\mathrm{a}-$ at frequency $f=5.5 \mathrm{MHz} ; \mathrm{b}-$ at frequency $f=10.0 \mathrm{MHz}$; $\mathrm{c}-$ at frequency $f=1.0 \mathrm{MHz}$

\section{Conclusions}

1. With the vibration amplitude $A=1.04 \mathrm{~mm}$, the maximum value of the volume density of the grain mass is reached. With a further increase in the vibration amplitude, the value of the volume density decreases to the grain's nature.

2. At a constant frequency of the electric field with increasing the humidity, the dielectric permeability of the grain increases. Its growth is observed with an increase in the temperature of the grain mass and it is $\left(0.011\right.$ per $^{\circ} \mathrm{K}$ to 0.015 per $\left.{ }^{\circ} \mathrm{K}\right)$ for the studied frequency range, therefore, temperature compensation is required.

3. Constant dependence of wheat grain "Bezostaya-1" on the vibration amplitude at different humidity and temperature for frequencies of $1 \mathrm{MHz}, 5.5 \mathrm{MHz}$ and $10 \mathrm{MHz}$ has an extreme. At the same time, in the range of vibration amplitudes of $0.5 \ldots 2 \mathrm{~mm}$, the relative change in DC is $8 \ldots 10 \%$, which allows to conclude that it is necessary to introduce stabilization of the vibration amplitude in the flow device for preparing grain samples.

\section{References}

[1] Nelson S. Dielectric Properties of Agricultural Materials and Their Applications. Academic Press, 2015. 229 p.

[2] Kent M. Electrical and dielectric properties of food materials: a bibliography and data. Science and Technology Publishers Ltd, 1987, 149 p. ISBN 0948323604.

[3] Ranjbaran M, Zare D, Simulation of energetic- and exergetic performance of microwave-assisted fluidized bed drying of soybeans, Energy Volume 59, 15 September 2013, pp. 484-493.

[4] Stetson L.E., Nelson S.O. Audiofrequency dielectric properties of grain and seed // Transaction of Engineering Research, 1981. vol. 26,2 - pp. 171-178.

[5] Azadi,M.S., Younesi, E. 2013. The effects of storage on germination characteristics and enzyme activity of sorghum seeds. Journal of Stress Physiology \& Biochemistry, Vol. 9(4), pp.289-298.

[6] Khairetdinova, A.F., Saitov, R.I., Abdeev, R.G., Talipov, N.S. 2012. A study of a hygrothermal method of grain moisture control in the drying process. Measurement techniques, Vol. 55(1), pp.104-107.

[7] Kok Y.Y., Hou K.M., Li L.Y., Jamaliah S., Zulkifly A. 2013. A Small and Slim Coaxial Probe for Single Rice Grain Moisture Sensing. Sensors, Vol. 13 (3), pp. 3652-3663.

[8] Meszaros P. Relationships between electrical parameters and physical properties of cereal grains, oilseeds, and apples PhD diss. Budapest, 2007. 